\title{
Preparation and Performance of Modified Montmorillonite-reinforced Wood-based Foamed Composites
}

\author{
Qingde Li, ${ }^{\text {a }}$ Yingyi Liang, ${ }^{\mathrm{b}}$ Feng Chen, ${ }^{\mathrm{c}, *}$ and Tonghui Sang ${ }^{\mathrm{d}}$ \\ Wood fiber was modified by impulse-cyclone drying treatment with poplar \\ and montmorillonite as reinforcing materials; mMMT/polypropylene/wood \\ fiber foaming composite was prepared by the hot compression process. \\ The effects of modification, temperature, and content of montmorillonite \\ on physical and mechanical properties of the composite were analyzed. \\ Mechanical properties, porosity, shrinkage, water absorption, and \\ thickness swelling tests showed that when mMMT reinforcement was 5 \\ wt $\%$, the best performance was achieved. The scanning electron \\ microscopy observations showed that bubble holes were distributed \\ widely and evenly, and mMMT appeared in the cell gap and was \\ encapsulated by polypropylene, which maximized the bonding effect. \\ Flexural strength was $27.5 \mathrm{MPa}$, flexural modulus was $2110 \mathrm{MPa}$, tensile \\ strength was $20.0 \mathrm{MPa}$, and impact strength was $6.30 \mathrm{KJ} / \mathrm{m}^{2}$. When \\ absolute volume of dense solid reached $70.8 \mathrm{~cm}^{3}$, porosity was $21.4 \%$ \\ and shrinkage was $1.17 \%$, which indicated that the water absorption \\ increased most remarkably under that test condition. When equilibrium \\ water absorption reached $9.28 \%$, the thickness swelling decreased by \\ $25 \%$. The results showed that mMMT effectively optimized mechanical \\ properties of wood-based foamed composites and improved hygroscopic \\ properties.
}

Keywords: Modified montmorillonite; Wood-based composite material; Porosity; Silane coupling agent; Azodicarbonamide

Contact information: a: School of Industrial Design and Ceramic Art, Foshan University, Foshan 528225, China; b: School of Medical Engineering, Foshan University, Foshan 528225, China; c: School of Art and Design, Taizhou University, Taizhou 318000, China; d: Faculty of Music and Performing Arts, Universiti Malaysia Kelantan, City Campus, Locked Bag 36, 16100 Pengkalan Chepa, Kota Bharu, Kelantan, Malaysia; *Corresponding author:47893729@qq.com

\section{INTRODUCTION}

Wood-based foamed composite (WFCs) material is based on the basic formula of wood-based composite material that is mixed with a foamer, nucleating agent, foaming auxiliary agent, and so on in a certain proportion of mass. This material is also heated and melted by plastic molding equipment to become a type of composite material with continuous and uniform distribution of foamed micropores (Wang et al. 2019). The industry of wood-based foam composites has developed rapidly in the past two decades (Kallakas et al. 2019). Wood fiber is a strong filling material (Yang et al. 2004; Gamelas and Ferraz 2015). The organic components in fiber are mainly cellulose, hemicellulose, and lignin, which lead to many shortcomings of WFCs, such as low ductility, low strength, poor internal bonding strength, and high density (Zhang et al. 2004; Wang et al. 2005; Choi et al. 2006). 
Adding a foamer can effectively optimize the properties of composites, such as reducing material consumption and improving surface hydrophobicity (Han et al. 2011). The use of foamer can also effectively reduce the weight and density of WPCs and improve mechanical properties. Therefore, it is important to add foamer in the process of wood-based composites.

Bledzki and Faruk found that the foamer could effectively reduce surface roughness of WPC by nearly 70\% (Bledzki and Faruk 2006). Matuana et al. (1997) found that cell morphology and quantity of foamed polyvinyl chloride (PVC)/wood fiber composite depended on the amount of plasticizer, surface treatment of wood fiber, gas saturation, and foaming conditions. Petchwattana's study concluded that when the size of foam hole increases, compressive and tensile strength of foamed composites decreases (Petchwattana and Covavisaruch 2011). Babaei et al. (2014) modified nanoclay with azodicarbonamide and then prepared foamed modified nanoclay/high-density polyethylene (HDPE)/wheat straw powder (WSP) composites using injection molding machines. The results showed that average pore size decreased $21.7 \%$ with the increase of pore density via addition of $200 \%$ to $400 \%$ modified nano-clay, and pore size further decreased with the increase of pore density when reinforcements reached $500 \%$. When the amount of modified nanoclay increased from $0 \%$ to $400 \%$, the water absorption increased to $19.3 \%$ and thickness swelling of samples was increased to $26.5 \%$, respectively. Mechanical properties of HPDE/WSF composite materials became optimal when two parts of modified nanoclay were added. It should also be noted that reinforcement of modified nanomaterials has a great negative impact on impact resistance of foamed composites (Babaei et al. 2014).

To improve physical and mechanical properties of foamed composites and uniformity of foaming, it is necessary to modify wood fiber to reduce its polarity. Common methods are chemical modification represented by alkali treatment, acylation, and graft copolymerization, and physical modification, represented by high temperature heat treatment and microwave treatment. Drying pretreatment of biomass is a common, effective, and environmentally friendly modification method. Impulse-cyclone drying treatment modification has the advantages of lower cost, shorter time, higher strength, a simpler process, and so on, which can degrade the wood fiber chemical composition. Hemicelluloses with poor thermal stability degrade first, and molecular chain fracture may occur in the process of degradation, and even lignin and cellulose microfibril may also break (Ding et al. 2019; Jonasson et al. 2019), which may lead to roughened wood fiber surface, enhanced depth to resin in high temperature mixed diffusion, and improved mechanical interlock ability. Impulse-cyclone drying treatment can also greatly reduce the number of free hydroxyl groups in wood fiber components, reduce polarity (Yu et al. 2020), and improve crystallinity of cellulose (Gao et al. 2019), so as to improve compatibility between the wood fiber and plastic matrix and improve dimensional stability (Okon and Udoakpan 2019) and mechanical properties of wood composites (Sun and $\mathrm{Wu} 2019)$.

In this study, cottonwood fiber and montmorillonite were used as reinforcing materials to modify wood fiber with an impulse-cyclone drying treatment. With woodbased foaming composites prepared by high temperature treatment, the influences of mMMT (modified montmorillonite) and foamer ADC (foamer azodicaramide) on properties of wood-based foaming composites were investigated. 


\section{EXPERIMENTAL}

\section{Materials}

The foamer azodicaramide (foamer ADC) was purchased from Shanghai Kamesh Biotechnology Co., Ltd. (Shanghai, China). Polypropylene (PP) was purchased from CNPC Daqing Petroleum Chemical Industrial Factory (Daqing, China). Leftovers of poplar were provided by Zhongshan Yong Xu Wood-Based Panel Company (Zhongshan, China). Maleic anhydride grafted polyethylene (MAPE) was purchased from Guangzhou Bai Chen Co., Ltd. (Guangzhou, China). Dryers, montmorillonite (MMT), $\mathrm{Na}_{2} \mathrm{SO}_{4}$, and vaseline were all purchased from Tianjin Benchmark Chemical Reagent Co., Ltd. (Tianjin, China).

The MMT and silane coupling agent were provided Zhejiang Feidian Chemical Co., Ltd., (Hangzhou, China).

\section{Methods}

Preparation of modified montmorillonite/polypropylene/wood fiber foamed composites

Poplar leftovers were processed into 40-mesh > 60-mesh wood fiber using a 60type wood fiber mill (Xingtai Maple Machinery Manufacturing Co., Ltd., Hebei, China), and placed in the forced convection constant temperature drying oven (101A-4HA; Shanghai Kanglu Instrument Equipment Co., Ltd., Shanghai, China) at $103{ }^{\circ} \mathrm{C}$ and dried to a moisture content of less than $3 \%$.

MMT and silane coupling agent were purchased from Zhejiang Feidian Chemical Co., Ltd. The structural formula of MMT is $(\mathrm{Al}, \mathrm{Mg})_{2}\left[\mathrm{Si}_{4} \mathrm{O}_{10}\right](\mathrm{OH})_{2} \cdot \mathrm{n} \mathrm{H}_{2} \mathrm{O}$. The MMT was dried to a moisture content of below 3\%, ground and screened using an 80 mesh sieve. The silane coupling agent $\left(\mathrm{KH}-550: \mathrm{NH}_{2} \mathrm{CH}_{2} \mathrm{CH}_{2} \mathrm{CH}_{2} \mathrm{Si}\left(\mathrm{OC}_{2} \mathrm{H}_{5}\right)_{3}\right)$ had a boiling point of $217{ }^{\circ} \mathrm{C}$. The MMT was mixed with silane coupling agent at a mass ratio of 100:4, fully mixed in a high-speed mixer with a temperature of $60{ }^{\circ} \mathrm{C}$ (GHV type; Tianjin Saide Electric Control Mechanical Equipment Co., Ltd., Tianjin, China), and then dried at $80{ }^{\circ} \mathrm{C}$ for $6 \mathrm{~h}$ to obtain mMMT. There were two functional groups in the silane coupling agent. One was reacted with hydroxyl group, and the other underwent a chemical reaction with functional groups in the plastic, or physical mixing with the polymer matrix was achieved, so that MMT and wood fiber were effectively linked together.

Impulse-cyclone drying (ICD) treatment has a short treatment time, high intensity, high efficiency, a simple process, and it is environmentally friendly. Wood fibers were first subjected to high-temperature hot air, which was generated using a heat generator, a screw feeder, an induced draft fan at a temperature of $220^{\circ} \mathrm{C}$, an inlet air velocity of 10 $\mathrm{m} / \mathrm{s}$, and a feed rate of $120 \mathrm{~kg} / \mathrm{h}$. The wood fiber was placed in a multi-function high temperature and high pressure water vapor treatment device generator with a temperature of $220{ }^{\circ} \mathrm{C}$ and a pressure of $0.6 \mathrm{MPa}$ for modification treatment, and the treatment time was $15 \mathrm{~min}$. Then it was placed in a constant temperature and humidity drying box under the condition of $105{ }^{\circ} \mathrm{C}$, and the moisture content of the wood fiber was dried to $3 \%$. Wood fiber, PP (T30S, Melt Indexer 2-3 g/10 min), MAPE (PE-12, HDPE: $\mathrm{MAH}=100: 1.5,190{ }^{\circ} \mathrm{C}, 2.16 \mathrm{~kg}$, melt indexer 1 to $4 \mathrm{~g} / 10 \mathrm{~min}$ ), lubricant (paraffin), mMMT, and foamer ADC were prepared according to the test piece ratio scheme and placed at room temperature. In a high-mixing machine, they were stirred and mixed for $15 \mathrm{~min}$ at high speed, made uniform, and then placed in the twin-screw extruder of SJSH30/SJ45 double-stage plastic extrusion unit (Yuyao Ludao Rubber \& Plastic 
Machinery Co., Ltd., Yuyao, China) for granulation. They were prepared by hot pressing at a high temperature using a PP 600D hot press machine (JingTuo Instrument Technology Co., Ltd., Tianjin, China). Paraffin was used as a lubricant, mMMT was used as an enhancer, and ADC was used as a foamer in this experiment. The specific formula is shown in Table 1. The specific experimental process is as follows.

White wood residue $\rightarrow$ wood powder $\rightarrow$ drying PP, MAPE and paraffin additives mMMT

Foamer ADC

Extrusion

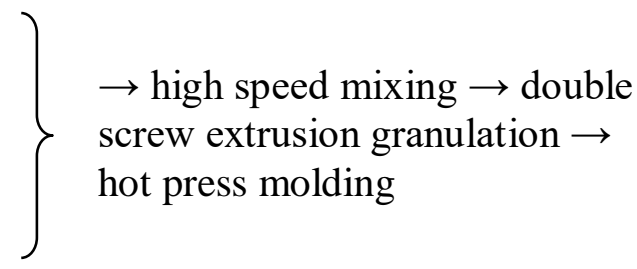

Extrusion molding process conditions were that the extruder screw tube temperature was between $145^{\circ} \mathrm{C}$ to $170{ }^{\circ} \mathrm{C}$, head temperature of $165^{\circ} \mathrm{C}$, host frequency was $22 \mathrm{~Hz}$, feeding speed of $45 \mathrm{r} / \mathrm{min}$, and cutting speed of $356 \mathrm{r} / \mathrm{min}$. The temperature settings of the twin screw extruder were $160{ }^{\circ} \mathrm{C}$ in zone $1,165^{\circ} \mathrm{C}$ in zone $2,170{ }^{\circ} \mathrm{C}$ in zone $3,170{ }^{\circ} \mathrm{C}$ in zone $4,185^{\circ} \mathrm{C}$ in zone $5,170{ }^{\circ} \mathrm{C}$ in zone 6 , and $165{ }^{\circ} \mathrm{C}$ in zone 7 . The speed of the extruder was set at $60 \mathrm{rpm}$. The prepared raw material particles were hotpressed using a zs-406b electric sulfur-adding molding machine (Zhuosheng Mechanical Equipment Co., Ltd., Dongwan, China). The temperature was set at $180{ }^{\circ} \mathrm{C}$, prepressed for $15 \mathrm{~min}$, hot-pressed for $10 \mathrm{~min}$ under $5 \mathrm{MPa}$, and cold-pressed for $5 \mathrm{~min}$. The thickness of the test piece was $4 \mathrm{~mm}$. The prepared $\mathrm{mMMT} / \mathrm{PP} /$ wood fiber foamed composites were then prepared into standard samples using an electric saw and dumbbelltype sample-making machine (Hongrui Precision Cutting Tools Co., Ltd., Dongwan, China). Finally, the modified montmorillonite reinforced wood-based foamed composite samples were prepared.

Table 1. Composition of Sample of Wood-based Foaming Composites

\begin{tabular}{|c|c|c|c|c|c|c|}
\hline $\begin{array}{c}\text { Sample } \\
\text { No. }\end{array}$ & PP & Wood Fiber & MAPE & Paraffin & Foamer ADC & mMMT \\
\hline 1 & $67 \%$ & $27 \%$ & $3 \%$ & $1 \%$ & $2 \%$ & $0 \%$ \\
\hline 2 & $67 \%$ & $27 \%$ & $3 \%$ & $1 \%$ & $2 \%$ & $3 \%$ \\
\hline 3 & $67 \%$ & $27 \%$ & $3 \%$ & $1 \%$ & $2 \%$ & $5 \%$ \\
\hline 4 & $67 \%$ & $27 \%$ & $3 \%$ & $1 \%$ & $2 \%$ & $7 \%$ \\
\hline 5 & $67 \%$ & $27 \%$ & $3 \%$ & $1 \%$ & $2 \%$ & $10 \%$ \\
\hline
\end{tabular}

Note: The total amount of PP, wood fiber, MAPE, paraffin, and foamer is 100 . the percentage of $\mathrm{mMMT}$ is a percentage of the total amount.

\section{FTIR analysis of modified montmorillonite}

The group changes before and after MMT modification were measured by Fourier transform infrared spectrometer (Magna-IR560; Thermo Nicolet Corporation, Madison, WI, USA). The tested samples were mixed with $\mathrm{KBr}$ powder and pressed into thin wafers for testing. The wavenumber scanning range was from $4000 \mathrm{~cm}^{-1}$ to $500 \mathrm{~cm}^{-1}$, the resolution was $4 \mathrm{~cm}^{-1}$, and the number of scans was 32 . 


\section{Micromorphological analysis}

Scanning electron microscopy (SEM) works on the basis of interaction between electrons and matter. That is, when a beam of high-energy incident electrons strikes the surface of a substance, the interaction between electron and substance is used to obtain a variety of physical and chemical information of each sample. During the test, the sample was prepared into small lumps with a cutter, and the section facing upward was made flat. Each sample was placed on the sample holder, both sides of the sample were glued with conductive carbon adhesive, and then the gold film was evaporated and sprayed in a vacuum coating machine (FEI Company, Hillsboro, OR, USA). The experimental process was tested in accordance with ASTM E1588 (2017). Morphology and characteristics of scanning electronic micro lens FEI QUANTA200 (FEI Company, Hillsboro, OR, USA) were observed at an accelerated voltage of $30 \mathrm{kV}$.

\section{Mechanical sample preparation and performance test}

The prepared mMMT/PP/wood fiber foam composite material was sawn into a standard test piece by a precision table saw (HW110L-50; Hongrui Precision Cutting Tools Co., Ltd., Dongwan, China) and a dumbbell-type sampler (BGD-5102; Bogda Testing Instrument Co., Ltd., Qingdao, China). There were 6 test pieces per group, wherein the impact test piece size was $80 \mathrm{~mm} \times 10 \mathrm{~mm} \times 4 \mathrm{~mm}$, bending sample size was $80 \mathrm{~mm} \times 13 \mathrm{~mm} \times 4 \mathrm{~mm}$, and tensile sample size was $165 \mathrm{~mm} \times 20 \mathrm{~mm} \times 4 \mathrm{~mm}$ ). Bending performance was tested according to ASTM D790 (2010), tensile performance was tested according to ASTM D638 (2010), and impact performance was tested according to ASTM D256 (2010).

The impact test method of plastics only supported beams showed that the test results were the arithmetic average of five samples. Mechanical strength of the test piece was measured with a WDW-20 electronic universal testing machine (Changchun Kexin Test Instrument Co., Ltd., Jilin, China) and observed with a scanning electron microscope (SEM-EDXA; FEI Company, Hillsboro, OR, USA) equipped with an energy spectrometer. Roughness and cracking degree of cross-section of the test piece were used to characterize microscopic morphology, such as size and uniformity of foam voids.

\section{Shrinkage sample preparation and testing}

The mixture of $67 \%$ PP, 27\% wood powder, and 3\% MAPE, 1\% paraffin, $2 \%$ foamer $\mathrm{ADC}$, and different amounts of mMMT were mixed with a high-mixer (GHV type; Tianjin Saide Electronic Control Machinery Equipment Co., Ltd., Tianjin, China). The mixture was obtained by extrusion granulation through a twin-screw extruder to obtain a raw material for injection molding, and then it was injection molded into a standard shrinkage test piece by a RPWXZSJ-8100 micro-injection molding machine (Shanghai Runpin Teaching and Research Center, Shanghai, China). Cylinder temperature was $185^{\circ} \mathrm{C}$, nozzle temperature was $200{ }^{\circ} \mathrm{C}$, injection pressure was $75 \mathrm{MPa}$, holding pressure was $70 \mathrm{MPa}$, pressure holding time was $10 \mathrm{~s}$, and injection speed was $40 \mathrm{~cm}^{3} / \mathrm{s}$. The standard sample size was $80 \mathrm{~mm} \times 10 \mathrm{~mm} \times 4 \mathrm{~mm}$. After stripping, the sample was placed at $23{ }^{\circ} \mathrm{C} \pm 2{ }^{\circ} \mathrm{C}$ for $6 \mathrm{~h}$ to $24 \mathrm{~h}$, and then the size of the spline was measured by Cpj-3020a / AZ Marriott projector (Yifeng Xintian Precision Instrument Co., Ltd., Suzhou, China). The experiment was conducted according to ASTM D2732 (2008) and Eq. 1 is as follows,

$$
S M_{\mathrm{P}}=100\left(L_{0}-L_{1}\right) / L_{0}
$$


where $S M_{\mathrm{P}}$ is the molding shrinkage $(\%), L_{0}$ is the cavity length $(\mathrm{mm})$, and $L_{1}$ is the sample length $(\mathrm{mm})$.

Sample preparation and testing of hygroscopic properties

According to the determination method ASTM D570-98 (2018), a SZ-3 panel saw machine (Hongrui Precision Cutting Tools Co., Ltd., Dongwan, China) was used to prepare mMMT/foam-wood-plastic composite material into a hygroscopic preparation absorption sample. The size of the sample was $10 \mathrm{~mm} \times 10 \mathrm{~mm} \times 4 \mathrm{~mm}$. The hygroscopic sample was placed in a constant temperature drying box at $103{ }^{\circ} \mathrm{C}$ until dry before the absorption experiment.

The chemical reagent $\left(\mathrm{Na}_{2} \mathrm{SO}_{4}\right)$ was separately placed into dryers to prepare a saturated solution with a relative humidity of $93 \%$. The indoor environment temperature was $20^{\circ} \mathrm{C}$. Then, each sample was placed in the corresponding dryer according to target relative humidity. Finally, vaseline was used to seal and store until saturation state. The test results were the averages of eight samples. After the sample reached equilibrium, sample weight was recorded as $W_{\mathrm{t}}$, and then the sample was dried in a drying box at 103 ${ }^{\circ} \mathrm{C}$ until it reached an absolute dry state. At this time, sample weight was recorded as $W_{0}$, and equilibrium moisture content of the sample was calculated as shown in Eq. 2,

$$
\operatorname{EMC}(\%)=\left[\left(W_{t}-W_{0}\right) / W_{0}\right] \times 100
$$

where $E M C$ is the equilibrium water content of the sample (\%), $W_{0}$ is the absolute dry weight of samples $(\mathrm{g})$, and $W_{\mathrm{t}}$ is the weight of sample after treatment $(\mathrm{g})$.

\section{RESULTS AND DISCUSSION}

\section{Preparation of Modified Montmorillonite}

The MMT and silane coupling agent were prepared with a mass ratio of 100:4, fully mixed in a high-speed mixing machine with a temperature of $60{ }^{\circ} \mathrm{C}$, and then dried at $80{ }^{\circ} \mathrm{C}$ for $6 \mathrm{~h}$ to obtain mMMT. The FTIR test showed that the basic framework of mMMT infrared spectrum did not change, and a new absorption peak appeared between 2838 and $3102 \mathrm{~cm}^{-1}$, which indicated that the coupling agent had been adsorbed on the surface of MMT particles.

\section{FTIR Analysis}

Figure 3 shows the infrared spectra of untreated wood fiber surface and modified wood fiber surface with impulse and cyclone high temperature treatment. Compared with untreated wood fiber (curve a), intensity of $\mathrm{OH}^{-1}$ absorption peak at $3430 \mathrm{~cm}^{-1}$ and $\mathrm{C}=\mathrm{O}$ absorption peak at $1738 \mathrm{~cm}^{-1}$ in modified wood fiber decreased, among which the hydroxyl absorption peak decreased remarkably. Xuan et al. (2017) also reported that surface-modified $\mathrm{TiO}_{2}$ nanoparticles on the anti-ultraviolet aging performance of woodbased Foamed Composites. For the A171-treated $\mathrm{TiO}_{2}$ (curve-4b), the broad absorption peak between $3400 \mathrm{~cm}^{-1}$ and $3200 \mathrm{~cm}^{-1}$ was weakened, and for the peak at around 1630 $\mathrm{cm}^{-1}$, the research results were similar. Under impact of impulse and cyclone high temperature treatment, free hydroxyl groups in molecular chains of wood cellulose had a "bridging" reaction with each other, and ether bonds were generated, which noticeably reduced the number of free hydroxyl groups on the surface of wood fiber. In addition, under impact of impulse and cyclone high temperature treatment, hemicellulose had a 
drastic degradation reaction, the acetyl group in hemicellulose was detached, and acetic acid was produced by hydrolyzation, which resulted in reduction of the number of carbonyl groups $\mathrm{C}=\mathrm{O}$.

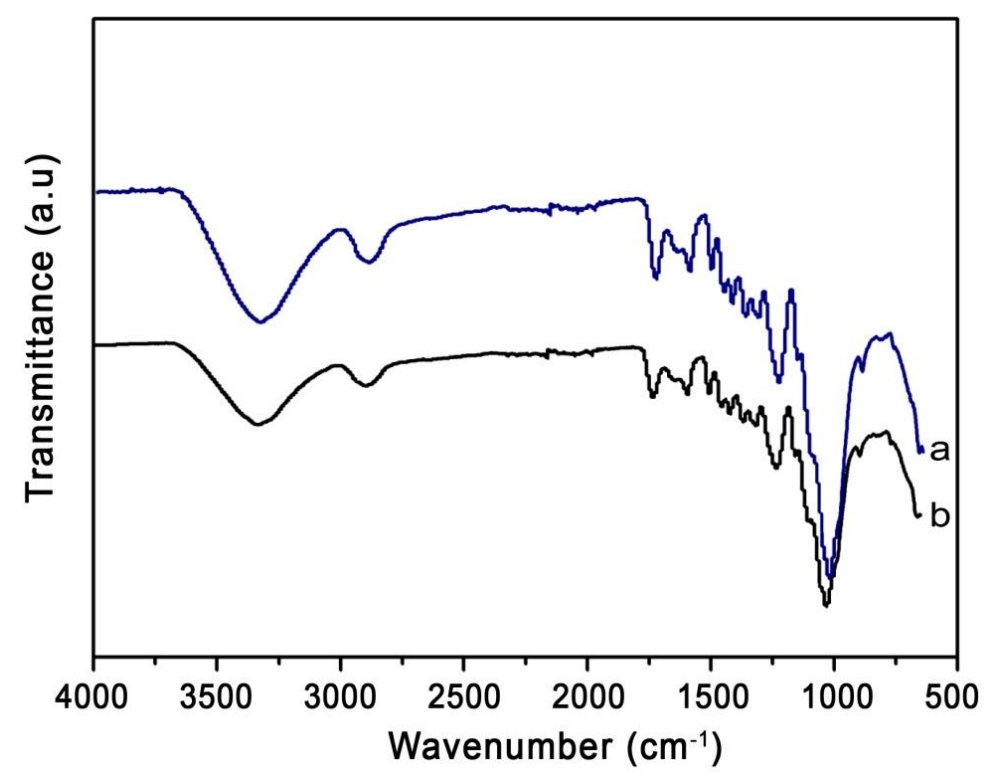

Fig. 1. Comparison of FTIR spectra obtained for wood fibers modified through impulse and cyclone high temperature treatment under different conditions: (a) untreated and (b) impulsecyclone high temperature treatment, $T=220^{\circ} \mathrm{C}$

\section{Effect of Modified Montmorillonite on Surface Microstructure of Wood- based Foamed Composites}

When modified montmorillonite/polypropylene/wood fiber foam composite was prepared using azodicarbonamide foamer, nitrogen gas was released and foamed. The foaming was relatively high, and the nucleation of bubbles was also good. Due to the hotpressing process, the surface of the material formed a hard skin due to drastic cooling, and pores were mostly formed inside the composite material. Bubble nucleation effects mainly have two cases: one is a composite material with a great amount of matrix in the bubble hole (Moscoso-Sánchez et al. 2013). In this case, the bubble holes were evenly distributed, and the pore-forming effect was better. The nucleation frequency was high as well. Therefore, under the effect of azobisformamide foamer, in modified montmorillonite/PP/wood fiber composite matrix, the sizes of bubble holes were evenly distributed with a small diameter and uniform distribution. The matrix composite materials formed high-quality foam. Nevertheless, an improper amount of azodicarbonamide foaming agent will lead to poor nucleation behavior of the foam in the composite matrix, which was improper azobisformamide dosage of foamer leading to poor the pore-forming effect in the composite matrix (Babaei et al. 2014). The bubble nucleation was not produced at the same time. Under action of azobisformamide, in the process of heating, air bubble nucleation formed step-by-step, which caused too large or too small of bubble hole sizes, unstable bubble hole density, and uneven distribution. Finally, the foaming matrix became an inferior foamer.

When the amount of mMMT added was $0 \mathrm{wt} \%$, distribution of cells on the fracture surface of sample 1 was observed by SEM. Foaming was uniform in the fracture surface, the fracture caused breakage of PP and wood fibers, and fracture occurred mostly 
in the cells. In the gap of the cells, fracture of wood fiber was clearly visible. Fracture of wood fiber, PP, and wood fiber carried most of the destructive force. The phenomenon where wood fiber was pulled out in the cell was good, and wood fiber was well-received by HDPE. The package was not exposed to the inner wall of the cell, which indicated that foamer ADC effectively foamed the PP (Faruk et al. 2007).

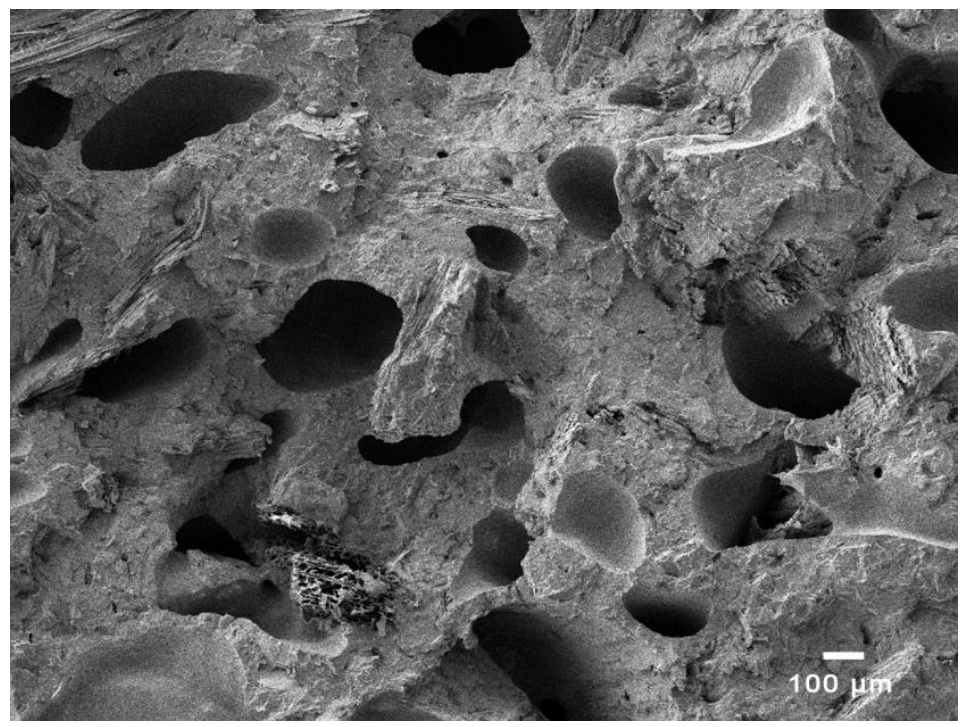

Fig. 2. SEM image of wood-based foaming composites with mMMT-0

Figure 3 shows the electron microscope image of mMMT/PP/wood fiber foamed composite. As shown in Fig. 3(a), mMMT reinforcement was 3wt\%. When the fracture surface of sample 2 with SEM was observed, bubble holes were evenly distributed. Distribution of mMMT appeared on the larger fracture surface between bubbles, and wood removal fibers and plastics that bore the destructive force were not affected by bubbles. At the same time, mMMT distributed in the bubble gap was transformed into the supporting structure of the material and played a further bonding role.

As shown in Fig. 3(b), when the fracture surface of sample 3 was observed by SEM under 100X, it was found that in sample 3 with $5 \mathrm{wt} \%$ mMMT reinforcement, the the number of bubble holes increased, and mMMT was evenly distributed in the gap of bubble holes. In mMMT/PP/wood fiber foamed composites, mMMT and wood fiber together formed the framework of material and played a good supporting role. Because diameter of wood fiber (40-mesh $>d \geq 60$-mesh) was longer than that of mMMT particle (80-mesh), mMMT with hard texture and small particle size filled in gaps of wood fibers, but they were well-wrapped by PP and were not exposed to the inner wall of blister holes, which maximized the binding effect of mMMT.

As shown in Fig. 3(c), mMMT reinforcement reached $7 \mathrm{wt} \%$, the bubble hole of foamed composite material decreased slightly, and diameter of the bubble hole began to decrease to approximately $120 \mu \mathrm{m}$. Wood fiber and mMMT constituted the framework of foaming material, because too much mMMT led to mixing and dispersion of wood fiber and PP, and PP could not play a good role in packaging. The small portion of mMMT was exposed to the inner wall surface of the bubble hole, which resulted in the decrease of reinforcing effect of $\mathrm{mMMT}$ and mechanical properties of $\mathrm{mMMT} / \mathrm{PP} /$ wood fiber foamed composites. 
As shown in Fig. 3(d), mMMT reinforcement increased to $10 \mathrm{wt} \%$. When fracture surface of sample 5 was observed by SEM, it was found that the bubble hole became uneven.
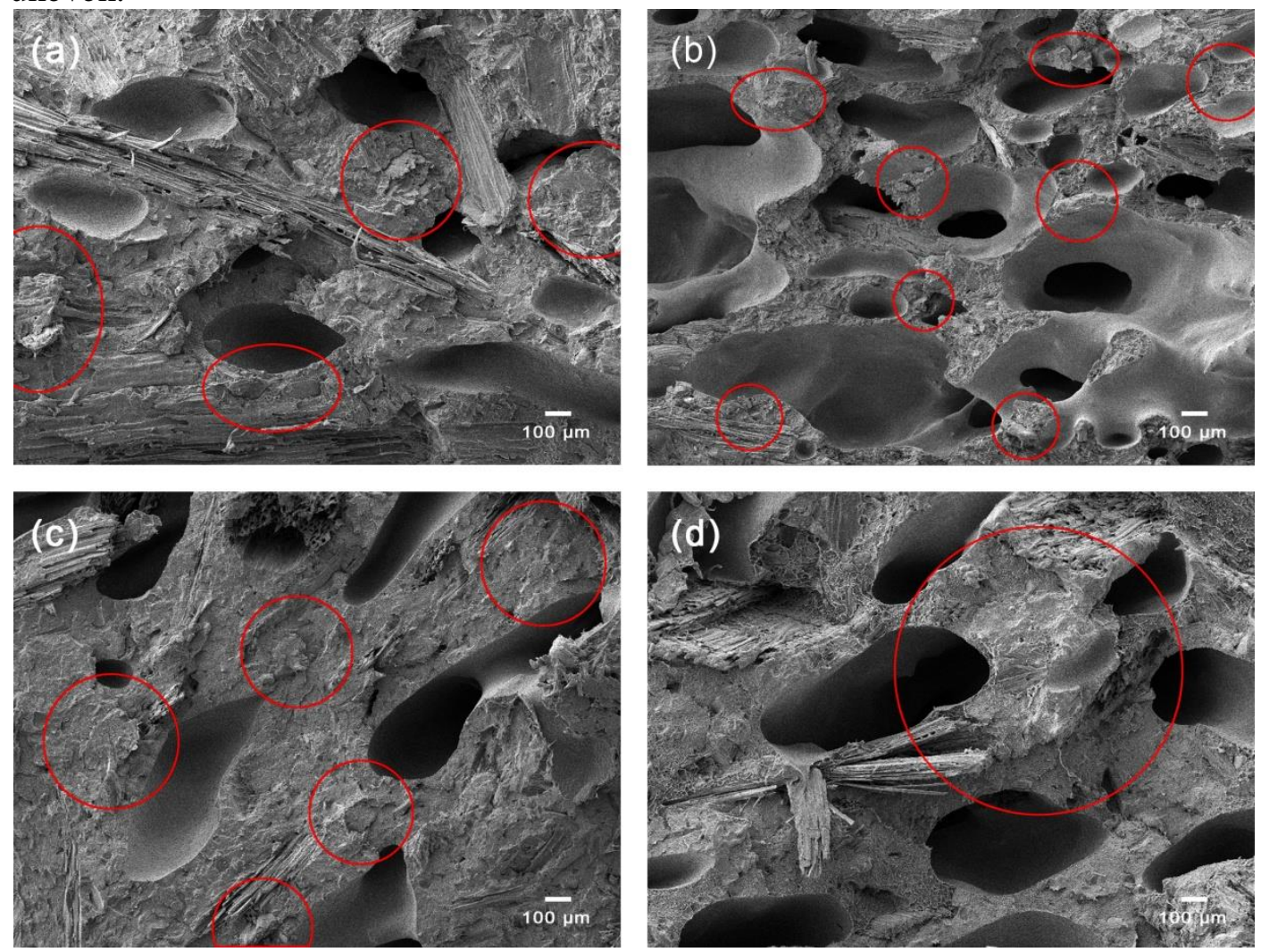

Fig. 3. 100X SEM images of wood-based foaming composites with different amounts of mMMT: (a) $3 \mathrm{wt} \% \mathrm{mMMT}$, (b) $5 \mathrm{wt} \% \mathrm{mMMT}$, (c) $7 \mathrm{wt} \% \mathrm{mMMT}$, and (d) $10 \mathrm{wt} \% \mathrm{mMMT}$

The agglomeration phenomenon of mMMT was observed at 100X. The mMMT contained $\mathrm{SiO}_{2}, \mathrm{Al}_{2} \mathrm{O}_{3}, \mathrm{MgO}$, and other minerals. Energy spectrum analysis showed that the composition inside the red area was mostly $\mathrm{SiO}_{2} \mathrm{Al}_{2} \mathrm{O}_{3}, \mathrm{MgO}$, and other mineral compositions. It could be determined that the material inside the red point in the picture was mMMT, as shown in Fig. 4. 


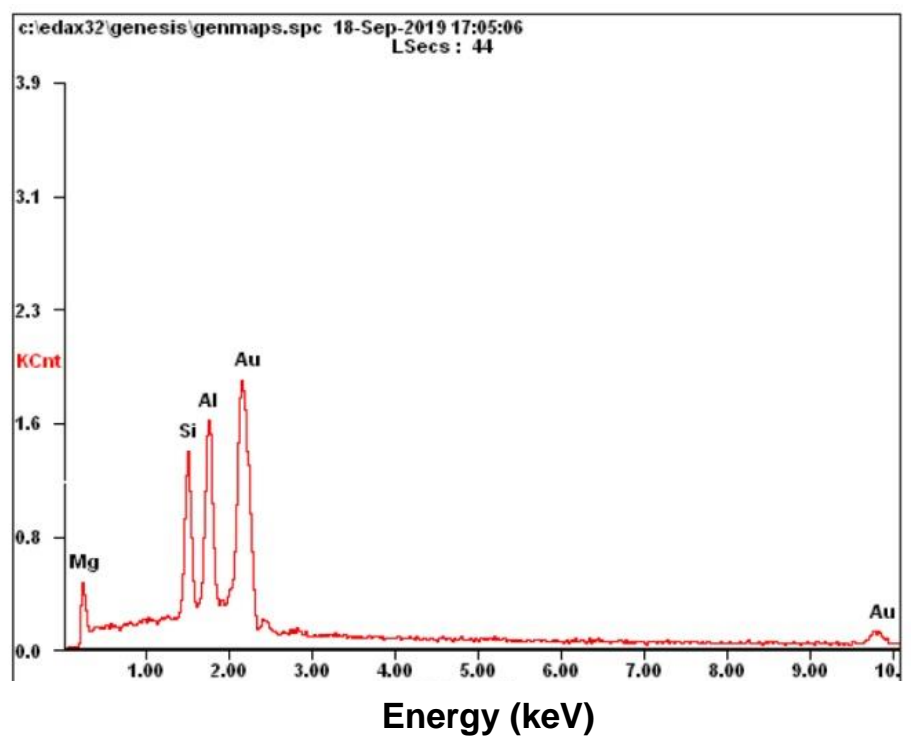

Fig. 4. Spectrum from Energy analysis of wood-based foaming composites

The fracture surface of sample 2 with SEM was observed. When mMMT reinforcement was $3 \mathrm{wt} \%$, bubble holes were evenly distributed than other samples as shown form Fig. 3. The chemical composition was fine, at approximately $0.2 \mu \mathrm{m}$ to 1 $\mu \mathrm{m}$. Reinforcement of mMMT particles was below $187.5 \mu \mathrm{m}$. The mMMT contained aquifer-like silicate minerals that belonged to a monoclinic system. These components have colloidal dispersion characteristics and are usually aggregated in bulk or soil under their own flocculation. Due to excessive mMMT reinforcement, agglomerated clay blocks were full of bubbles, and mMMT was largely exposed to the inner wall surface of bubbles, which affected the mixed contact surface between wood fiber and PP, destroyed the wrapping effect of PP, and finally led to further decline of mechanical properties of foamed composites.

In summary, azodicarbonamide foamer was used to prepare modified montmorillonite/polypropylene/wood fiber foaming composite. The mass ratio of foamer and substrate was 2:100. An electric sulfur adding molding machine was used to mold raw material particles by hot-pressing, and the temperature was set at $180{ }^{\circ} \mathrm{C}$, which could effectively improve nucleation density and nucleation of bubbles, which made the matrix filler melt quickly. Preloading for $15 \mathrm{~min}$ made azodicarbonamide foamer dissolve and disperse well in polypropylene/wood fiber melt, which improved nucleation of bubbles. At the same time, modified montmorillonite was integrated into the melt again, which formed a "bridging" effect with polypropylene. When matrix filler was fixed at $100 \mathrm{~g}$, final volume and size of polypropylene/wood fiber melt were quantified, which further improved nucleation density and bubble hole density. The cold-pressing method performed for 5 min made the melt surface form hard skin rapidly. Then, the melt was finalized, and modified montmorillonite was integrated into the pore wall of the foam hole, which formed a skeleton supporting function and further enhanced mechanical properties of foamer WPCs. The $\mathrm{mMMT} / \mathrm{PP} /$ wood fiber foamed composites with reinforcement of $5 \mathrm{wt} \% \mathrm{mMMT}$ and $2 \mathrm{wt} \%$ azodicarbonamide foamer had the best properties. 


\section{Effect of Modified Montmorillonite on Mechanical Properties of Wood- based Foamed Composites}

As shown in Table 2, mMMT reinforcement effectively enhanced mechanical properties of foamed wood-plastic composites. Reinforcements of mMMT in the samples were $0 \mathrm{wt} \%, 3 \mathrm{wt} \%, 5 \mathrm{wt} \%, 7 \mathrm{wt} \%$, and $10 \mathrm{wt} \%$, respectively. According to the comparison of mechanical properties of the samples, reinforcement performances of mMMT were as follows: flexural strength was from $19.73 \mathrm{MPa}$ to $27.53 \mathrm{MPa}$, bending elastic modulus was $1229.89 \mathrm{MPa}$ to $2112.04 \mathrm{MPa}$, tensile strength was from 11.68 to $19.95 \mathrm{MPa}$, fraction elongation was from 2.67 to $1.86 \%$, and impact strength was from $3.52 \mathrm{KJ} / \mathrm{m}^{2}$ to $6.30 \mathrm{KJ} / \mathrm{m}^{2}$.

Flexural strength and impact strength of sample 3 improved. Compared with sample 3, flexural strength, tensile strength, and elongation at break of sample 5 decreased. It was found that there was more mMMT in sample 5 than sample 3 by SEM. The mMMT was largely exposed to the inner wall surface of bubbles, destroyed the wrapping effect of PP, and finally led to further decline of mechanical properties of foamed composites.

Table 2. Mechanical Properties of Wood-based Foaming Composites

\begin{tabular}{|c|c|c|c|c|c|}
\hline $\begin{array}{c}\text { Sample } \\
\text { No. }\end{array}$ & $\begin{array}{c}\text { Flexural } \\
\text { Strength (MPa) }\end{array}$ & $\begin{array}{c}\text { Flexural } \\
\text { Modulus (MPa) }\end{array}$ & $\begin{array}{c}\text { Elongation at } \\
\text { Break (\%) }\end{array}$ & $\begin{array}{c}\text { Tensile Strength } \\
(\mathrm{MPa})\end{array}$ & $\begin{array}{c}\text { Impact Strength } \\
\left(\mathrm{KJ} / \mathrm{m}^{2}\right)\end{array}$ \\
\hline 1 & $19.73 \pm 0.98$ & $\begin{array}{c}1229.89 \pm \\
27.48\end{array}$ & $2.67 \pm 0.23$ & $11.68 \pm 0.83$ & $3.52 \pm 0.41$ \\
\hline 2 & $23.36 \pm 0.93$ & $\begin{array}{c}1554.38 \pm \\
26.26\end{array}$ & $2.34 \pm 0.24$ & $16.61 \pm 1.25$ & $5.91 \pm 0.64$ \\
\hline 3 & $27.53 \pm 0.85$ & $\begin{array}{c}2112.04 \pm \\
21.95\end{array}$ & $2.19 \pm 0.19$ & $19.95 \pm 1.56$ & $6.30 \pm 0.71$ \\
\hline 4 & $25.86 \pm 1.16$ & $\begin{array}{c}1924.27 \pm \\
23.37\end{array}$ & $2.05 \pm 0.15$ & $14.95 \pm 1.32$ & $4.34 \pm 0.54$ \\
\hline 5 & $25.54 \pm 1.25$ & $\begin{array}{c}1921.40 \pm \\
25.59\end{array}$ & $1.86 \pm 0.18$ & $13.68 \pm 1.55$ & $4.27 \pm 0.50$ \\
\hline
\end{tabular}

As shown in Figs. 5(a) and 5(b), both flexural strength and flexural modulus of sample 3 showed an upward trend. The maximum flexural strength reached $27.5 \mathrm{MPa}$, with an increase of $7.8 \mathrm{MPa}$, which represents a $28.3 \%$ increase. It was indicated that reinforcement of $5 \mathrm{wt} \% \mathrm{mMMT}$ increased bearing pressure in the compression area above the rectangular uniform section of the sample, and tensile resistance in the tensile area below the section also increased. In the process of wood fiber and plastic bonding, mMMT played the role of strengthening the matrix of foamed composite material. Flexural strength of sample 5 began to show a downward trend, decreasing $1.99 \mathrm{MPa}$ (7.2\%). This showed that more than 5 wt $\%$ mMMT exhibited an agglomeration phenomenon, which played an obstacle role in the composite process of wood fiber and $\mathrm{PP}$, leading to a decline in flexural strength. When mMMT reinforced quantity reached 5 $\mathrm{wt} \%$, the bending modulus of sample 3 rose and bent easily.

As shown in Fig. 5(c), when mMMT reinforcement reached $5 \mathrm{wt} \%$, elongation at break of sample 3 decreased $1.0 \%$, with a decline of $12.2 \%$. There was little change in tensile strength or elongation at break for this occasion. When mMMT reinforcement exceeded $5 \mathrm{wt} \%$, the elongation at break of sample 4 and sample 5 showed a decreasing 
trend. Such variation law indicated that when mMMT reinforcement was too much, it could not bond well with wood fiber. When mMMT reinforcement reached $10 \mathrm{wt} \%$, the decrease in amplitude was $14.20 \%$. As a result, stress-bearing capacity of the matrix was reduced, and a large number of bubble holes occupied the matrix of the material, which resulted in a decline in absolute compactness volume and tensile area of the matrix, making it fracture under relatively small tensile force. Compared with sample 1, bending modulus of sample 5 increased $882 \mathrm{MPa}$, with an increase percentage of $41.8 \%$. When mMMT reinforcement reached $10 \mathrm{wt} \%$, bending modulus of sample 5 decreased to 1921 $\mathrm{MPa}$, and still increased by $692 \mathrm{MPa}$ compared with sample 1 . This showed that $\mathrm{mMMT/PP/wood} \mathrm{fiber} \mathrm{foamed} \mathrm{composites} \mathrm{were} \mathrm{prone} \mathrm{to} \mathrm{bend} \mathrm{and} \mathrm{deform} \mathrm{under} \mathrm{bending}$ stress. When bending deformation occurred, foamed composites occupied part of the volume space of the material, which led to deformation, reduced brittleness, and increased toughness of the matrix (Ghasemi et al. 2012). The role of mMMT in reinforcing the matrix also played an important role, which made the wood foam. The elastic limit of composites was further improved.

As shown in Fig. 5(d), tensile strength increased first and then decreased as the amount of mMMT was increased. When mMMT reinforcement reached $5 \mathrm{wt} \%$, tensile strength of sample 3 reached $20.0 \mathrm{MPa}$, with an increase of $41.4 \%$. When mMMT reinforcement exceeded $5 \mathrm{wt} \%$, tensile strength of sample 4 and sample 5 showed a decreasing trend, which indicated that when mMMT reinforcement was too high, PP and wood fiber could not bond well, and this led to a decrease in stress-bearing capacity of the substrate, where mMMT caused it to fracture under relatively small tensile force.

As shown in Fig. 5(e), when mMMT reinforcement was $5 \mathrm{wt} \%$, impact strength of sample 3 reached the maximum value of $6.30 \mathrm{KJ} / \mathrm{m}^{2}$, which increased $2.78 \mathrm{KJ} / \mathrm{m}^{2}$ compared with that of sample 1 , with an increase of $44.1 \%$. This indicated that mMMT was better filled between PP and wood fiber, which resulted in the bonding effect. When impact force was received, there were many cracks on the surface that absorbed a large amount of impact energy and thereby improved impact resistance of wood-based foamed composites. When mMMT reinforcement reached $10 \mathrm{wt} \%$, impact strength of sample 5 decreased to $4.27 \mathrm{KJ} / \mathrm{m}^{2}$, with a decrease of $32.2 \%$. The main reason was that the impact process mainly absorbed impact force through generation and expansion of cracks. When too much mMMT was added, its reinforcement was too high, and mMMT was prone to the phenomenon of uneven dispersion, agglomeration, and other phenomena, and was exposed to the inner wall of the bubble hole, resulting in a decline of impact capacity of the hole wall, and impact strength decreased instead of increasing. 

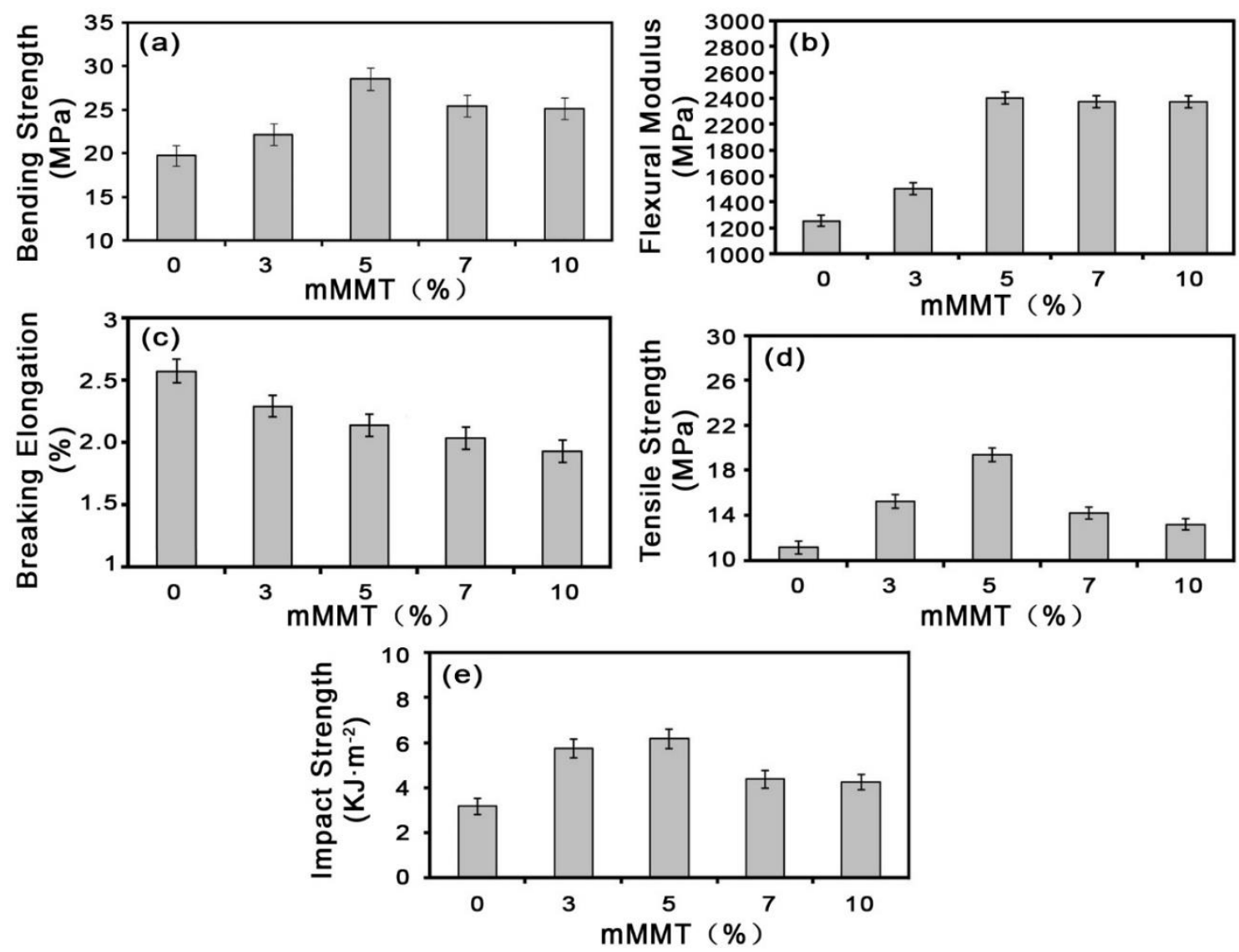

Fig. 5. Effects of amount of mMMT added on mechanical properties of wood-based foaming composites: (a) flexural strength, (b) flexural modulus, (c) elongation at break, (d) tensile strength, and (e) impact strength

After comprehensive consideration, different proportions of mMMT were filled in wood-based foamed composites, and mechanical properties were tested as follows: with the increase of filling amount of mMMT, flexural strength, flexural modulus, tensile strength, and impact properties of $\mathrm{mMMT} / \mathrm{PP} /$ wood fiber foamed composite showed a trend of first increasing and then decreasing, and elongation at break showed a decreasing trend. Mechanical properties of $\mathrm{mMMT} / \mathrm{PP} /$ wood fiber foamed composites were optimized when mMMT reinforcement was $5 \mathrm{wt} \%$.

\section{Effect of Modified Montmorillonite on Shrinkage and Porosity of Wood- based Foamed Composites}

Table 3 shows the effect of mMMT on porosity and shrinkage of wood-based foaming composites. Reinforcement of mMMT in the samples 1 through 5 were $0 \mathrm{wt} \%, 3$ $\mathrm{wt} \%, 5 \mathrm{wt} \%, 7 \mathrm{wt} \%$, and $10 \mathrm{wt} \%$, respectively. When mMMT/PP/wood fiber foamable composite samples were prepared with a thezs-406b electric sulfur-adding molding machine, the packing mass was $100 \mathrm{~g}$ and volume of the hot-pressing mold was $15 \mathrm{~cm} \times 15 \mathrm{~cm} \times 0.4 \mathrm{~cm}$. Absolute compacted volume of the sample was measured by Eq. 3 (Xi et al. 2017):

$$
\text { Porosity }(\%)=\frac{(\text { Apparent volume } 160)-(\text { Absolute compacting volume })}{\text { Apparent volume }} \times 100 \%
$$


Injection material was obtained using the twin-screw extruder, and then it was injected into the standard shrinkage sample by the RPWXZSJ-8100 micro-injection molding machine. The standard sample was placed in an oven to be dried for $2 \mathrm{~h}$, and then dried at a constant temperature of $23{ }^{\circ} \mathrm{C}$ for $48 \mathrm{~h}$ after being removed. The length of the spline was measured with a measuring projector. The size $(\mathrm{mm})$ of the plastic part was recorded as $M$, length $(\mathrm{mm})$ of the mold was recorded as $D$, and absolute shrinkage $(\%)$ of material was recorded as $S$. Shrinkage and porosity of mMMT reinforced woodbased foamed composites were calculated by Eq. 1 and Eq. 3, as shown in Table 3.

Table 3. Effects of Amount of mMMT Added on Shrinkage and Porosity of WoodBased Foaming Composites

\begin{tabular}{|c|c|c|c|}
\hline Sample No. & $\begin{array}{c}\text { Absolute Compacting } \\
\text { Volume }\left(\mathrm{cm}^{3}\right)\end{array}$ & Shrinkage (\%) & Porosity (\%) \\
\hline 1 & $70.86 \pm 2.01$ & $1.35 \pm 0.15$ & $21.25 \pm 2.76$ \\
\hline 2 & $70.82 \pm 2.08$ & $1.26 \pm 0.11$ & $21.31 \pm 2.40$ \\
\hline 3 & $70.75 \pm 2.12$ & $1.17 \pm 0.09$ & $21.39 \pm 2.58$ \\
\hline 4 & $71.33 \pm 2.16$ & $1.22 \pm 0.10$ & $20.75 \pm 2.16$ \\
\hline 5 & $73.38 \pm 2.23$ & $1.28 \pm 0.12$ & $18.47 \pm 2.02$ \\
\hline
\end{tabular}

Table 3 shows that foamed wood-plastic composite reinforced by mMMT was determined by the proportion of each component. When mMMT reinforcement was 5 $\mathrm{wt} \%$, absolute compacted volume value of sample 3 was $70.8 \mathrm{~cm}^{3}$, porosity reached $21.4 \%$, and shrinkage was only $1.17 \%$. Although porosity was high, shrinkage was lowest in the preparation process, which led to the largest bubble hole and even foaming. With the increase of mMMT reinforcement, the absolute compatibility volume value corresponding to $\mathrm{mMMT} / \mathrm{PP} /$ wood fiber foamed composite showed an overall trend of increasing, with the maximum increasing range of $73.4 \mathrm{~cm}^{3}$. The trend of porosity was opposite to that of absolute compacting volume value. When absolute compacting volume value increased, porosity correspondingly decreased.

The mMMT used for strengthening wood-based foamed composites was approximately 80-mesh with small particles. After extrusion, mMMT particles of MMT reinforced wood-plastic composites were filled in the pores of wood fiber, which resulted in a decrease in porosity and a rise in density of PP/wood-fiber foamed composites. Ceramic structure was changed, and hardness increased at high temperature. While increasing the support strength of wood-based foamed composite skeleton, it also promoted shrinkage of material. Therefore, mMMT/PP/wood fiber foam composite with enhanced mMMT had a higher absolute volume value and a lower shrinkage ratio, and absolute compact volume value was inversely proportional to shrinkage ratio.

\section{Effects of Modified Montmorillonite on Water Absorption and Thickness Swelling of Wood-based Foamed Composites}

Water absorption test

Figure 6 shows the effect of different mMMT reinforcements on water absorption of wood-based foaming composite materials. The mMMT reinforcements for the samples were $0 \mathrm{wt} \%, 3 \mathrm{wt} \%, 5 \mathrm{wt} \%, 7 \mathrm{wt} \%$, and $10 \mathrm{wt} \%$, respectively. Water absorption of 
$\mathrm{mMMT/PP/wood} \mathrm{fiber} \mathrm{foam} \mathrm{composite} \mathrm{was} \mathrm{caused} \mathrm{by} \mathrm{a} \mathrm{large} \mathrm{number} \mathrm{of} \mathrm{cavities,} \mathrm{foam}$ holes, and hydroxyl and polar groups in the wood fiber foam composite, as well as some cracks and gaps between wood fiber and resin matrix interface. Compared with sample 1 with no reinforced mMMT, after reinforced mMMT foamed wood-plastic composite materials, the water absorption of the other samples first increased and then decreased with the increase of the added amount. Among them, bibulous absorption of sample 3 (mMMT) $5 \mathrm{wt} \%$ increased the most noticeably. Equilibrium water absorption was $9.28 \%$, which was $5.14 \%$ higher than that of sample $1(4.14 \%)$ without reinforcing mMMT.

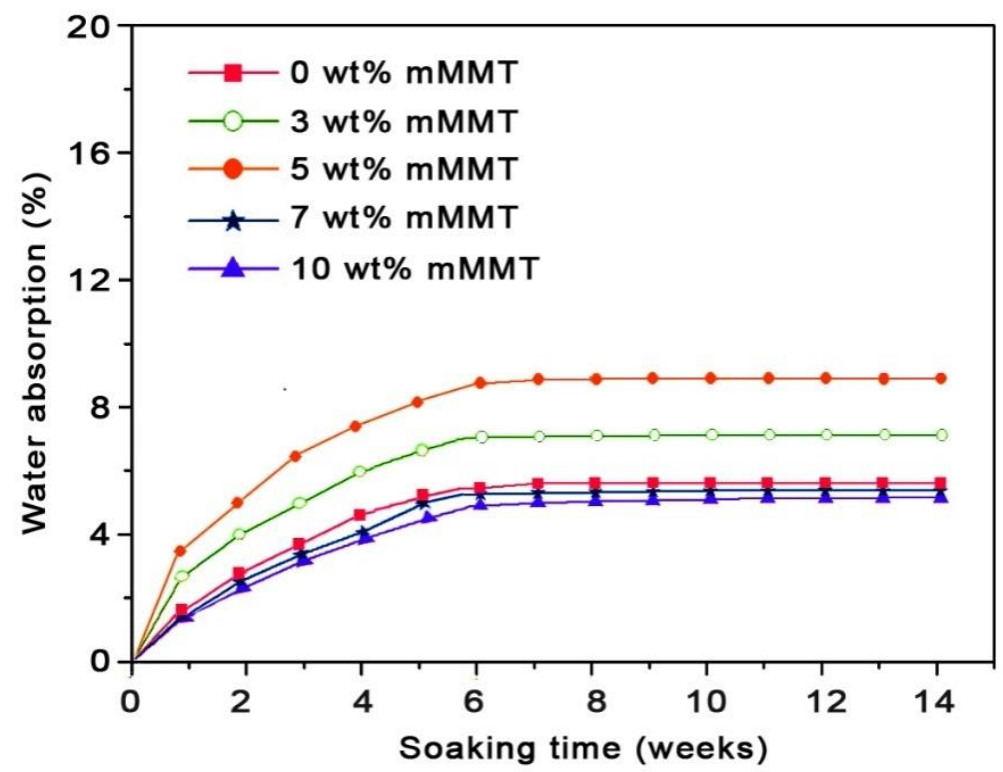

Fig. 6. Water absorption of wood-based foaming composites with different amounts of mMMT

During the experiment, with the increase of soaking time of samples, water absorption of both wood-based foam composites without mMMT and composites with mMMT noticeably increased, and water absorption of composite material reached a balance after 10 weeks, and water absorption of the wood-based foam composite increased remarkably at the beginning of the sample experiment ( 0 weeks to 6 weeks). Under treatment of silane modifier, hydroxyl on the surface of mMMT reacted with silane coupling agent, which led to decreases of hydroxyl number, polarity, and water absorption. In addition, in the mixing process, wood fiber was packed by mMMT and PP and further blocked contact between wood fiber and water so that water absorption of wood fiber was reduced. When mMMT reinforcement was $5 \mathrm{wt} \%$, the mixture was the most even, the bubble hole diameter produced inside the material was the largest, and its water absorption was the highest. When mMMT reinforcement was too high, mMMT appeared to demonstrate agglomeration phenomenon, which produced even foam holes. Diameter of foam holes decreased, leading to decreased water absorption.

\section{Thickness swelling test}

Figure 7 shows the influence of different mMMT reinforcements on thickness swelling of $\mathrm{mMMT} / \mathrm{PP} /$ wood fiber foam composite material. The mMMT reinforcements of samples 1 through 5 were $0 \mathrm{wt} \%, 3 \mathrm{wt} \%, 5 \mathrm{wt} \%, 7 \mathrm{wt} \%$, and $10 \mathrm{wt} \%$, respectively. Compared with sample 1 , with increased soaking time of samples, thickness swelling of 
foam wood-plastic composites both without mMMT and with mMMT noticeably increased, and they reached a balance after 10 weeks. The thickness swelling of samples at the beginning of the experiment ( 0 weeks to 6 weeks) was higher. Among them, thickness swelling of foamed wood-plastic composites with $5 \mathrm{wt} \% \mathrm{mMMT}$ reinforcement decreased the most remarkably, with a decrease of $25 \%$.

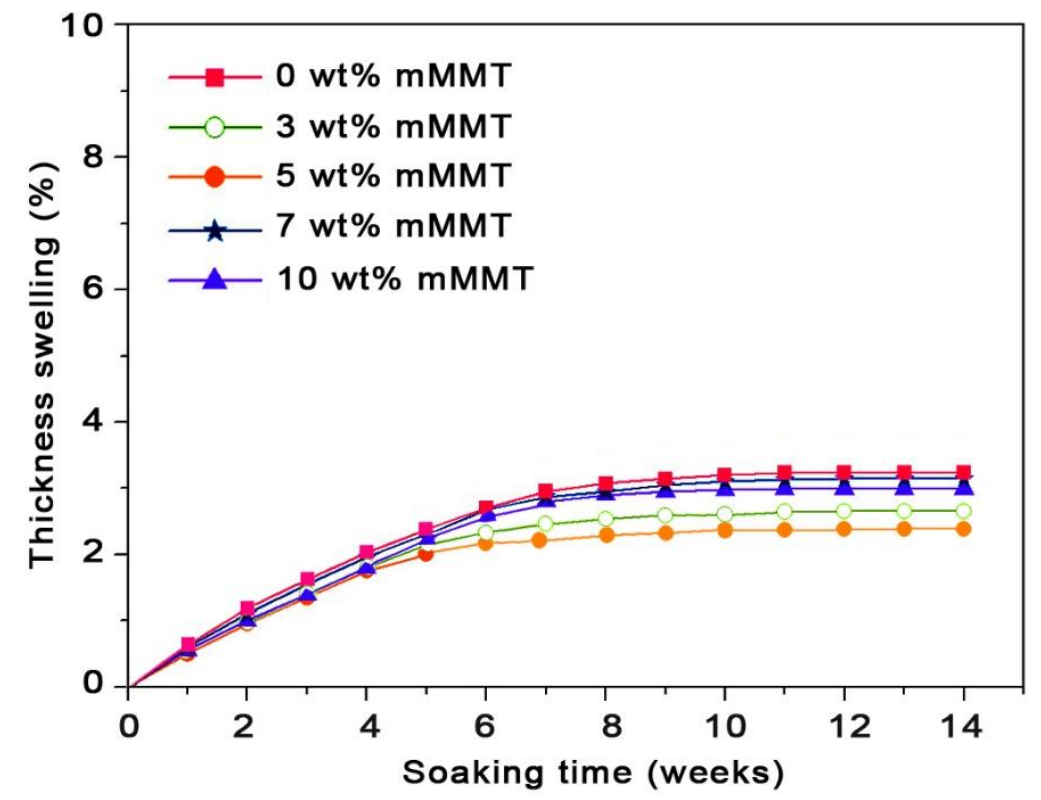

Fig. 7. Thickness swelling of wood-based foaming composites with different amounts of mMMT

Because thickness swelling of foamed wood-plastic composite increased with the increase of water absorption, it had a similar trend with water absorption. Wood fibers and mMMT constituted the framework of foaming materials. When mMMT reinforcement was too high, it led to mixing and dispersion of wood fiber and PP, and PP could not play a big role in wrapping. This led to decreases in strength of the foam material itself, and wood fiber that would be exposed to the outside and expand after absorbing water, leading to the uneven surface of the sample and the increase of thickness swelling.

\section{CONCLUSIONS}

1. The research results showed that reinforcement with a certain amount of mMMT could effectively improve performance of wood-based foam composite and enhance skeleton support function of wood-based foam composites. However, when the amount of reinforcement was excessive, the enhancement effect showed a downward trend.

2. Azodimethylamide foamer released nitrogen at $180{ }^{\circ} \mathrm{C}$ and foamed. Due to the hotpressing process, the surface of the material was hard because of drastic cooling, and the pores were mostly formed in the interior of the composite material.

3. The SEM observation showed that bubble holes increased in the fracture surface of sample 3 with $5 \mathrm{wt} \%$ mMMT reinforcement, which was observed at $100 \mathrm{X}$. 
Additionally, MMT was evenly distributed in the cell gap and was well-encapsulated by PP, but not exposed to the inner wall of the cell. The bonding effect of mMMT was maximized. When mMMT reinforcement increased to $10 \mathrm{wt} \%$, bubble holes in the fracture surface became uneven. The mMMT agglomeration was then observed at 100X. With mMMT being largely exposed to the inner wall surface of foam holes, the mixing contact surface between wood fiber and PP was affected, which destroyed the wrapping function of PP, and finally led to further decline in mechanical properties of foamed composites.

4. Mechanical property test results showed that flexural strength was $27.5 \mathrm{MPa}$ and the increase was $28.3 \%$ when mMMT reinforcement was 5 wt $\%$. Flexural modulus increased by $41.8 \%$ to $2110 \mathrm{MPa}$. Breaking elongation decreased $12.2 \%$ to $2.2 \%$ of original length. Tensile strength was $20.0 \mathrm{MPa}$ with an increase of $41.5 \%$. Impact strength was $6.30 \mathrm{KJ} / \mathrm{m}^{2}$, with an increase of $44.1 \%$. The increase was obvious, and mechanical properties of wood-based foamed composites were effectively optimized. When mMMT reinforcement exceeded $5 \mathrm{wt} \%$, mechanical properties began to decline and elongation at break presented a consistent trend of decline.

5. The shrinkage and porosity tests showed that when mMMT reinforcement was 5 wt $\%$, absolute density volume value of wood foam composite was $70.8 \mathrm{~cm}^{3}$, porosity was $21.4 \%$, and the shrinkage was $1.17 \%$. Absolute density volume value was inversely proportional to shrinkage. The test of water absorption and thickness swelling showed that when mMMT reinforcement was $5 \mathrm{wt} \%$, water absorption of foam composite increased noticeably, equilibrium water absorption was $9.28 \%$, with an increase of $5.14 \%$. Thickness swelling decreased remarkably by $25 \%$. When mMMT reinforcement exceeded $5 \mathrm{wt} \%$, the water absorption decreased, while the thickness swelling increased.

\section{ACKNOWLEDGMENTS}

This work was financially supported by the National Natural Science Foundation of China (Grant No. 31901243)

\section{Author Contributions}

Qingde Li and Feng Chen conceived of, designed, and performed the experiments. Qingde Li, Yingyi Liang, and Tonghui Sang analyzed and discussed the data. Qingde Li wrote the manuscript, with revisions by Feng Chen.

\section{REFERENCES CITED}

ASTM D256 (2010). "Standard test methods for determining the Izod pendulum impact resistance of plastics," ASTM International, West Conshohocken, PA, USA.

ASTM D570-98 (2018). "Standard test method for water absorption of plastics," ASTM International, West Conshohocken, PA, USA.

ASTM D638-10 (2010). "Standard test method for tensile properties of plastics," ASTM International, West Conshohocken, PA, USA. 
ASTM D790-10 (2010). "Standard test methods for flexural properties of unreinforced and reinforced plastics and electrical insulating materials," ASTM International, West Conshohocken, PA, USA.

ASTM D2732-08 (2008). "Standard test method for unrestrained linear thermal shrinkage of plastic film and sheeting," ASTM International, West Conshohocken, PA, USA.

ASTM E1588-17 (2017). "Standard practice for gunshot residue analysis by scanning electron microscopy/energy dispersive X-ray spectrometry," ASTM International, West Conshohocken, PA, USA.

Babaei, I., Madanipour, M., Farsi, M., and Farajpoor, A. (2014). "Physical and mechanical properties of foamed HDPE/wheat straw flour/nanoclay hybrid composite," Compos. Part B-Eng. 56, 163-170. DOI:

10.1016/j.compositesb.2013.08.039

Bledzki, A. K., and Faruk, O. (2006). "Injection moulded microcellular wood fibrepolypropylene composites,” Compos. Part A-Appl. S. 37(9), 1358-1367. DOI: 10.1016/j.compositesa.2005.08.010

Choi, N.-W., Mori, I., and Ohama, Y. (2006). "Development of rice husks-plastics composites for building materials," Waste Manage. 26(2), 189-194. DOI: 10.1016/j.wasman.2005.05.008

Ding, D., Li, P., Zhang, X., Ramaswamy, S., and Xu, F. (2019). "Synergy of hemicelluloses removal and bovine serum albumin blocking of lignin for enhanced enzymatic hydrolysis," Bioresource Technol. 273, 231-236. DOI: 10.1016/j.biortech.2018.11.024

Faruk, O., Bledzki, A. K., and Matuana, L. M. (2007). "Microcellular foamed wood plastic composites by different processes: A review," Macromolecular Materials and Engineering 292(2), 113-127. DOI: 10.1002/mame.200600406

Gamelas, J. A. F., and Ferraz, E. (2015). "Composite films based on nanocellulose and nanoclay minerals as high strength materials with gas barrier capabilities: Key points and challenges," BioResources 10(4), 6310-6313. DOI: 10.15376/biores.10.4.63106313

Gao, Z., Huang, R., Chang, J., Li, R., and Wu, Y. (2019). "Effects of pressurized superheated-steam heat treatment on set recovery and mechanical properties of surface-compressed wood," BioResources 14(1), 1718-1730. DOI: 10.15376/biores.14.1.1718-1730

Ghasemi, I., Farsheh, A. T., and Masoomi, Z. (2012). "Effects of multi-walled carbon nanotube functionalization on the morphological and mechanical properties of nanocomposite foams based on poly (vinyl chloride)/(wood flour)/(multi-walled carbon nanotubes)," Journal of Vinyl and Additive Technology 18(3), 161-167. DOI:10.1002/vnl.20299

Han, Y., Manolach, S. O., Denes, F., and Rowell, R. M. (2011). "Cold plasma treatment on starch foam reinforced with wood fiber for its surface hydrophobicity," Carbohyd. Polym. 86(2), 1031-1037. DOI: 10.1016/j.carbpol.2011.05.056

Jonasson, S., Bünder, A., Niittylä, T., and Oksman, K. (2019). "Isolation and characterization of cellulose nanofibers from aspen wood using derivatizing and non-derivatizing pretreatments," Cellulose 27(1),1-19. DOI: 10.1007/s10570-019-02754-w

Kallakas, H., Ayansola, G. S., Tumanov, T., Goljandin, D., Poltimäe, T., Krumme, A., and Kers, J. (2019). "Influence of birch false heartwood on the physical and mechanical properties of wood-plastic composites," BioResources 14(2), 3554-3566. DOI: 10.15376/biores.14.2.3554-3566 
Matuana, L. M., Park, C. B., and Balatinecz, J. J. (1997). "Processing and cell morphology relationships for microcellular foamed PVC/wood-fiber composites," Polym. Eng. Sci. 37(7), 1137-1147. DOI: 10.1002/pen.11758

Okon, K. E., and Udoakpan, U. I. (2019). "Physicochemical properties of Pinus massoniana wood subjected to silicone oil heat treatment," Maderas-Cienc. Tecnol. 21(4), 531-544. DOI: 10.4067/S0718-221X2019005000409

Petchwattana, N., and Covavisaruch, S. (2011). "Influences of particle sizes and contents of chemical blowing agents on foaming wood plastic composites prepared from poly(vinyl chloride) and rice hull," Mater. Des. 32(5), 2844-2850. DOI: 10.1016/j.matdes.2010.12.044

Sun, Z., and Wu, M. (2019). "Effects of sol-gel modification on the interfacial and mechanical properties of sisal fiber reinforced polypropylene composites," Ind. Crop. Prod. 137, 89-97. DOI: 10.1016/j.indcrop.2019.05.021

Wang, W., Sain, M., and Cooper, P. A. (2005). "Hygrothermal weathering of rice hull/HDPE composites under extreme climatic conditions," Polym. Degrad. Stabil. 90(3), 540-545. DOI: 10.1016/j.polymdegradstab.2005.03.014

Wang, Q., Xiao, S., and Shi, S. Q. (2019). "The effect of hemicellulose content on mechanical strength, thermal stability, and water resistance of cellulose-rich fiber material from poplar," BioResources 14(3), 5288-5300. DOI: 10.15376/biores.14.3.5288-5300

Xi, J., Zhou, E., Liu, Y., Gao, W., Ying, J., Chen, Z., and Gao, C. (2017). "Wood-based straightway channel structure for high performance microwave absorption," Carbon 124, 492-498. DOI: 10.1016/j.carbon.2017.07.088

Xuan, L., Han, G., Wang, D., Cheng, W., Gao, X., Chen, F., and Li, Q. (2017). "Effect of surface-modified $\mathrm{TiO}_{2}$ nanoparticles on the anti-ultraviolet aging performance of foamed wheat straw fiber/polypropylene composites," Materials 10(5), 456. DOI: $10.3390 /$ jcm9030793

Yang, H.-S., Kim, H.-J., Son, J., Park, H.-J., Lee, B.-J., and Hwang, T.-S. (2004). 'Ricehusk flour filled polypropylene composites; mechanical and morphological study," Compos. Struct. 63(3-4), 305-312. DOI: 10.1016/S0263-8223(03)00179-X

Yu, W., Xu, B., Fan, B., Zhang, Y., and Wang, X. (2020). "Effects of saturated steam treatment on the cell-wall mechanics and moisture sorption properties of kenaf fibers," BioResources 15(1), 159-171. DOI: 10.15376/biores.15.1.159-171

Zhang, H., Rizvi, G. M., and Park, C. B. (2004). "Development of an extrusion system for producing fine-celled HDPE/wood-fiber composite foams using $\mathrm{CO}_{2}$ as a blowing agent," Adv. Polym. Tech. 23(4), 263-276. DOI: 10.1002/adv.20016

Article submitted: December 16, 2019; Peer review completed: February 13, 2020; Revised version received and accepted: March 18, 2020; Published: March 30, 2020. DOI: 10.15376/biores.15.2.3566-3584 